\title{
SI engine fuel mixture type indicator and an assessment of its suitability of an economic driving style
}

ARTICLE INFO

Received: 15 July 2021

Revised: 8 August 2021

Accepted: 16 August 2021

Available online: 8 September 2021
The article presents the structure and a principle of operation of a simple indicator of the type of a fuel-air mixture supplying a spark-ignition engine with a direct fuel injection. The designed indicator was tested, as a result of which its correct operation was verified. By using information from the indicator, it was possible to assess its usefulness for assisting the driver in an economical driving style. Preliminary studies show that thanks to the use of the developed indicator, it is possible to save about 10\% of fuel as a result of the correction of the economic driving style on the route selected for the purpose of this research paper. The target of this study was to confirm a noticeable reduction in fuel consumption when supplying the engine with a stratified mixture. In order to obtain more accurate data, the research should be extended to include a greater number of routes and its division into urban and non-urban areas.

Key words: SI engine with direct fuel injection, stratified and homogeneous mixture, mixture type indicator, economical driving style, fuel consumption

This is an open access article under the CC BY license (http://creativecommons.org/licenses/BY/4.0/)

\section{Introduction}

SI engines are still used to drive passenger cars. Most of them are powered by direct fuel injection into the combustion chamber. This type of fuel injection allows the combustion of very lean fuel-air mixtures by their stratification in the combustion chamber. Burning lean mixtures makes better use of the fuel and thus reduce its consumption. A spark ignition engine can operate on a stratified mixture only within a limited range of speeds and loads [1, 2]. It also requires a specific thermal state of the engine and the exhaust system, including the catalytic reactor. For these reasons, it is the engine control unit that decides which mixture is supplied to the engine: stratified (economical) or homogeneous.

There was a question posed: could the driver of the car, having information about the type of a fuel mixture at the given moment, change the driving style to a more economical one? In order to answer this question, the plan was to build a simple indicator of the type of a fuel mixture supplying the SI engine with a direct fuel injection and to conduct tests in road conditions. The indicator was built and tests were conducted on the Mitsubishi Carisma GDI car.

The presented research paper on the construction of a mixture type indicator is an engineering diploma thesis at studies in the automotive field, the author and promoter of which are the authors of this paper.

\section{Knowledge analysis}

Spark ignition engines are powered by fuel-air mixtures of various compositions. The amount of fuel contained in the air-fuel mixture is determined by the air-fuel equivalence ratio $\lambda$. The composition of the air-fuel mixture affects the main parameters of the engine performance such as: power output, fuel consumption and the content of toxic components in the exhaust gasses. Until recently, SI engines were supplied with almost homogeneous air-fuel mixtures. Combustion of such mixtures in the SI engine does not allow to use up all the fuel they contain. It is known that the higher the value of the coefficient ratio $\lambda$, the more fuel contained in the mixture will be burnt. At the same time, it is known that mixtures with the coefficient $\lambda>1.4$ do not ignite from the spark. The solution that allows for the combustion of very lean mixtures is layering of the mixture in the combustion chamber. It consists in the formation of a rich mixture around the electrodes of the spark plug and progressively poorer in the areas further away from the spark plug as far as the air itself at the walls of the combustion chamber. Such a load may have an average composition defined by the factor $\lambda$ above the value considered to be a flammable mixture (ignitable by an ignition spark). Mitsubishi was the first make in the world to use GDI (Gasoline Direct Injection) engines in the mass produced Carisma model, which burn stratified mixtures. Their combustion allows to reduce fuel consumption in the range of lower engine speeds and engine power. This translates into a reduction in fuel consumption when driving the car, mainly at a constant speed, up to approx. $100 \mathrm{~km} / \mathrm{h}$.

A driver who wishes to use an economical driving style should try to drive primarily on stratified mixtures $[5,6]$. Unfortunately, the manufacturer did not install any indicator informing the driver about the type of mixture the engine is supplied with. Three types of mixtures can be distinguished in the power supply of the Mitsubishi Carisma GDI engine:

- homogeneous air-fuel mixture (uneconomical),

- stratified air-fuel mixture (economical),

- air only (during the so-called engine braking).

In SI engines with direct gasoline injection, a homogeneous mixture is created by injecting fuel into the combustion chamber at the beginning of the fill stroke. As a result of the air turbulence, it evaporates and mixes with air during the filling and compression strokes. A stratified mixture occurs when fuel is injected into the combustion chamber at the end of the compression stroke, just before ignition. The 
position of the injector in the cylinder head is such as to direct the jet of injected fuel towards the electrodes of the spark plug. Fuel injection just before ignition prevents it from evaporating and mixing with the entire volume of air in the combustion chamber. In this way, the charge in the combustion chamber is stratified, i.e. correspondingly rich in the vicinity of the spark plug electrodes and progressively poorer in the areas closer to the walls of the combustion chamber. The average value of the factor $\lambda$ of a stratified charge in this way is outside the flammability range.

The formation of a stratified mixture and its combustion in the engine depends on many factors. Rotational speed, load, thermal condition and more have an influence on the type of the mixture that is generated and burned. This is determined by the engine control unit $[3,4]$.

It is known that many of the processes supervised by the ECU are optimized. The authors of this research paper did not find reliable information whether the method of selecting the type of mixture was optimized in terms of low fuel consumption. This issue became the reason for taking up the topic.

\section{Construction of the air-fuel mixture type indicator}

\subsection{Design assumptions for the indicator of the type of a combustion mixture}

By analyzing the method of creating fuel mixtures supplying the SI engine by direct fuel injection into the combustion chamber, it is possible to link the fuel injection phase with the type of a fuel-air mixture. Early (at the beginning of the filling stroke) fuel injection creates a homogeneous mixture (Fig. 1a). Late fuel injection (at the end of the compression stroke, just before ignition) creates a layered mixture (Fig. 1b).

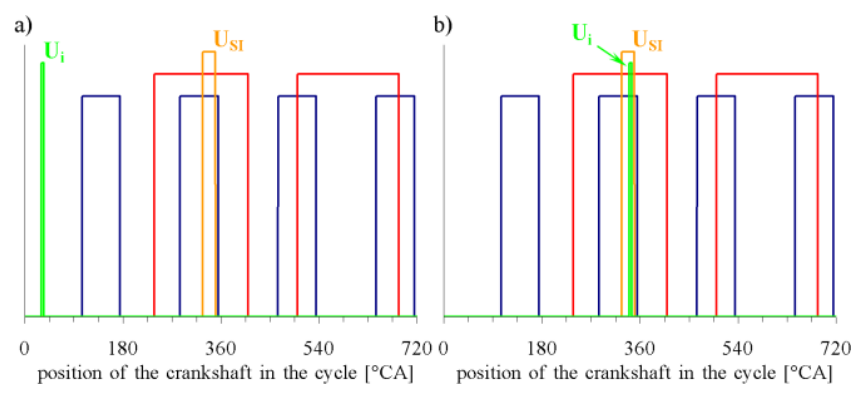

Fig. 1. Waveforms in the direct fuel injection system, when the mixture is formed: a) homogeneous, b) stratified

The navy blue waveforms show impulses from the crankshaft position sensor, while the red ones show the pulses from the camshaft position sensor. Based on these, it was possible to scale the axis of the angular position of the crankshaft for the first cylinder. The duty cycle begins when the piston is at TDC before its fill stroke and the crankshaft is assigned an angle of $0^{\circ} \mathrm{CA}$. Completion of the duty cycle occurs when the piston reaches TDC after the exhaust stroke and the crankshaft is assigned an angle of $720^{\circ} \mathrm{CA}$.

In order to determine the fuel injection phase (i.e. early, late), it is necessary to check whether the injection pulse $U_{i}$ occurs simultaneously with the ignition pulse $\mathrm{U}_{\mathrm{SI}}$. In Figure $1 \mathrm{a}$, the pulses occur at different times, determining the formation of a homogeneous mixture. In Figure $1 \mathrm{~b}$, the pulses occur at the same time, defining the formation of a stratified mixture. In this situation question should be posed whether at each point of the engine operation the mutual position of the injection pulse relative to the ignition pulse is as unambiguous as in Fig. 1. The following cases may raise doubts:

- high, close to maximum rotational speed and long injection time (Fig. 2a),

- low engine speed or idle running and short injection time (Fig. 2b).

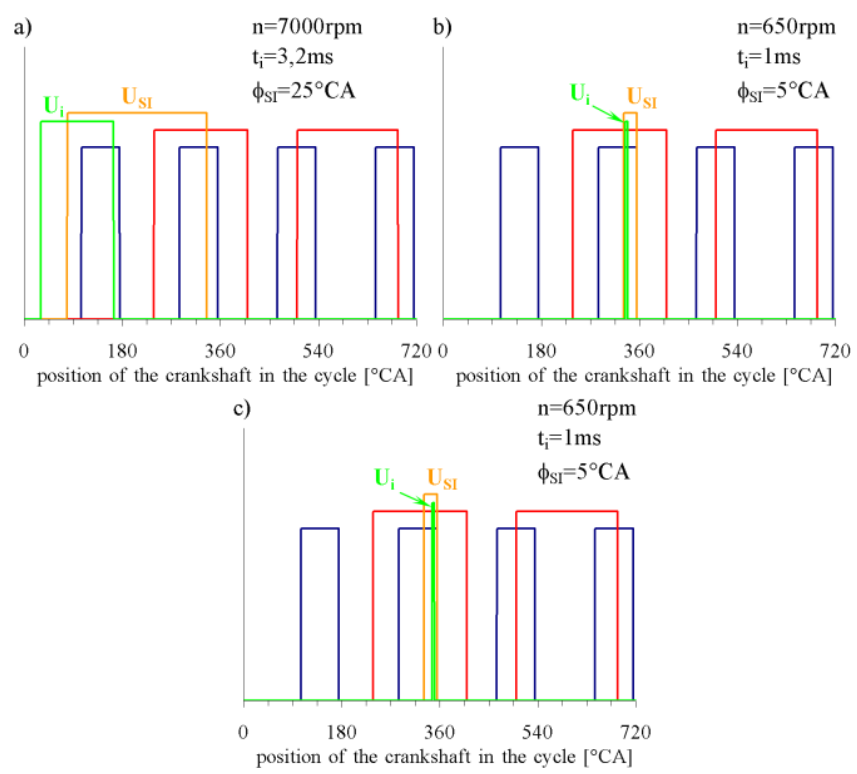

Fig. 2. Waveforms in situations giving rise to doubts as to the unambiguity of the assessment of the fuel-air mixture type

If the simultaneous occurrence of injection and ignition pulses is treated as a state indicating the formation of a stratified mixture, the waveforms in Fig. 2a misrepresent the formation of a stratified mixture. It is obvious that at high revs the engine is powered by a homogeneous mixture. Thus, the coexistence of signals is not always true information about the type of a mixture being created. A better method of determining the type of the mixture turned out to be checking the occurrence of the ignition pulse at the moment of the rising slope of the injection pulse. In this case, the signals shown in Fig. 2a correctly determine the formation of a homogeneous mixture. Figures $2 \mathrm{~b}$ and $2 \mathrm{c}$ show two cases of the mutual position of the $U_{i}$ and $U_{S I}$ pulses, specific for the formation of a stratified mixture. Determining a type of a mixture by examining the ignition signal at the moment of the rising slope of the injection pulse will give an erroneous result for the signals shown in Fig. 2 b. The question arises whether the engine controller, when supplying the engine with a stratified mixture, generates an injection impulse early enough for its rising slope to occur before the appearance of the ignition impulse. The literature [8] presents experimental studies of the Mitsubishi Carisma GDI engine control unit.

They show that the case of the mutual position of the ignition and injection pulses shown in Fig. $2 b$ does not occur when the ECU controls the operation of the engine. 
For low engine speeds and low engine loads, the injection start angle is approximately $320^{\circ} \mathrm{CA}$. Ignition advance angle of approx. $25^{\circ} \mathrm{CA}$, therefore an ignition pulse that is always $6.1 \mathrm{~ms}$ starts earlier than the injection pulse.

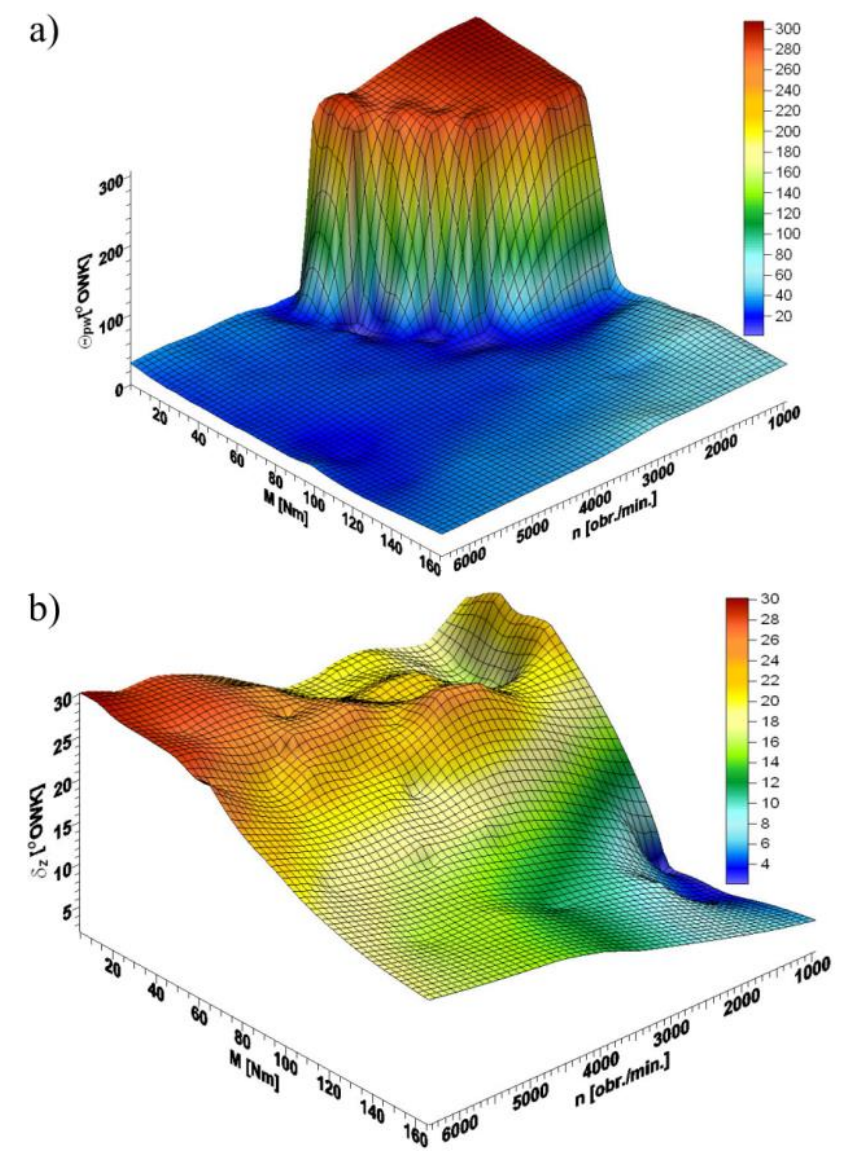

Fig. 3. Maps of: injection start angle (a) and ignition advance angle (b) for Mitsubishi Carisma GDI engine [8]

To sum up, on the basis of the mutual position of the injection and ignition pulses, it is possible to unequivocally determine the type of the formed fuel-air mixture. For this purpose, the occurrence of the ignition pulse during the rising slope of the injection pulse should be tested. The occurrence of the ignition pulse is confirmed by the formation of a stratified mixture, and its absence of a homogeneous mixture.

There is another condition in the SI engine management system in which the fuel is not injected. This is the case of engine braking. No injection pulse is generated. In subsequent cycles, the type of mixture will not be determined in the manner described above. In order to signal this state as well, it is necessary to test the occurrence of the injection pulse in each cycle in which the ignition pulse occurs. The ignition pulse is generated by the engine control unit in each cycle, regardless of the presence of an injection pulse. For both the homogeneous mixture and the stratified mixture, the fuel injection takes place before the ignition occurs (Fig. 1). Therefore, the falling slope of the ignition pulse is the moment when the occurrence of the injection pulse in the current work cycle should be checked. It is therefore necessary to remember the injection pulse at least until ignition. A way to do this is to generate an auxiliary signal that remembers the injection $\mathrm{I}_{\mathrm{ip}}$ at least for the remembering time $t_{i p m}$ from the occurrence of $U_{i}$ until the moment of ignition at the lowest rotational speed. (Fig. 4). Figures $4 \mathrm{a}$ and $4 \mathrm{~b}$ show the injection signal that was remembered in the event of loss of the injection signal after the formation of a homogeneous mixture. Figures $4 c$ and $4 d$ show the injection signal that was remembered in the event of loss of the injection signal after the formation of a stratified mixture. The method described above will allow for a detection of the no injection after no more than $t_{i p m}$.

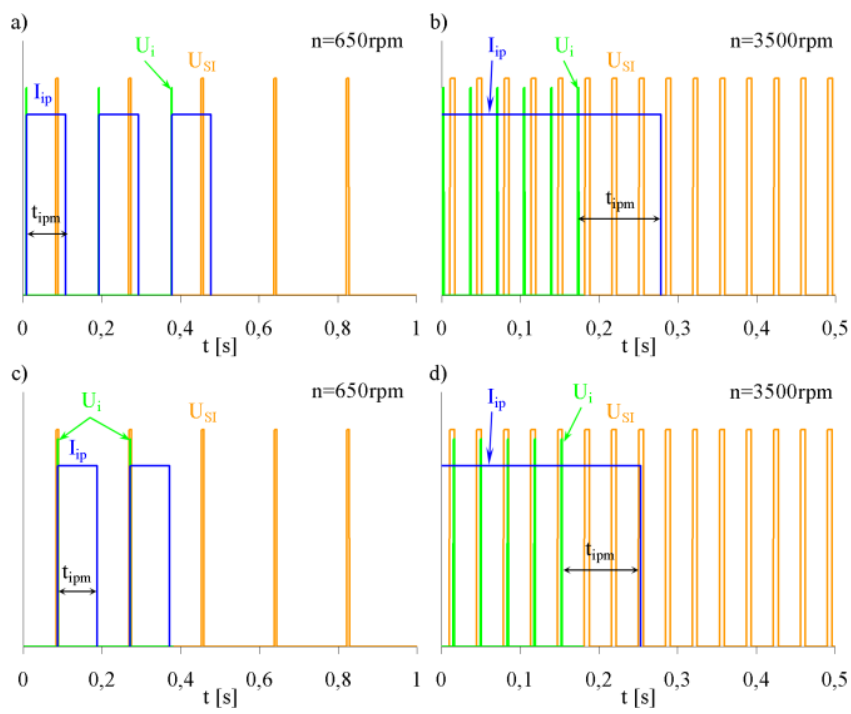

Fig. 4. Auxiliary injection signal at low (a) and high (b) engine rotational speed

The injection pulse elongation time should be equal to the time of two strokes at the minimum rotational speed $n=$ $=600 \mathrm{rpm}$, i.e. $\mathrm{t}_{\mathrm{ipm}}=0.1 \mathrm{~s}$. At higher rotational speeds, the $\mathrm{U}_{\text {ip }}$ signals generated for individual injection pulses will overlap creating one pulse ending at $t_{p}$ from the time of the last injection pulse [7].

\subsection{Construction of the mixture type indicator}

The device is to inform the driver about one of the three types of fuel-air mixtures with which the engine combustion chambers are filled. For this purpose a three-colour (RGB) LED was used. It was assumed that the colour:

- green will indicate a stratified mixture - as the most economical one,

- red will indicate a homogeneous mixture - as less economical,

- blue will indicate no fuel injection.

In the design assumptions, injection and ignition signals were selected to evaluate the type of a mixture supplying the SI engine with a direct gasoline injection. It was assumed that these are two-state signals in a simple form. The presented method of analyzing the type of mixture can be based on simple elements of digital electronics, e.g. flipflops. Due to the place of use of the indicator, TTL technology was selected as more appropriate for use in automotive technology. Elements made in this technology are more resistant to interference and damage (mainly electrostatic).

In the next step, the diagram of the Mitsubishi Carisma GDI engine control system was analyzed in order to obtain 
the required signals for the indicator being built. The injection signal for the first cylinder is available on pin no. 1 of the engine ECU, and the ignition signal on pin no. 3. These signals were assessed for compliance with the TTL technique. It turned out that they do not comply with the TTL standard (Fig 5).
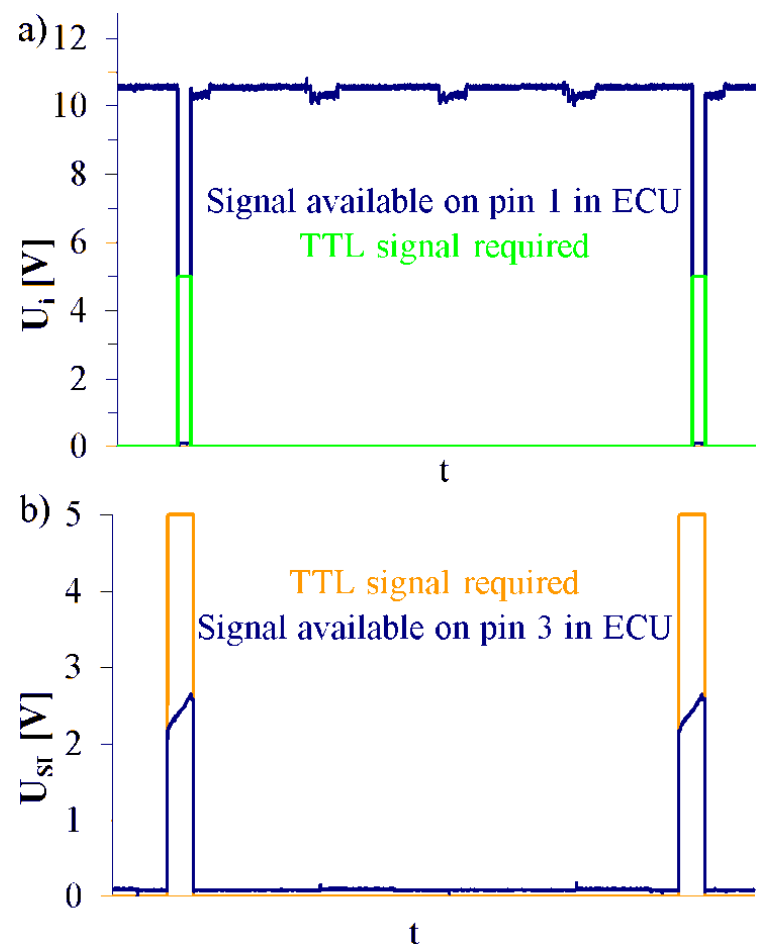

Fig. 5. Injection and ignition signals available in the GDI engine of a Mitsubishi Carisma

Thus, the constructed indicator requires a system that adjusts the signals available in the engine control system to the TTL standard.

The electronic system was designed and built, the block diagram of which can be seen in Fig. 6 [7].

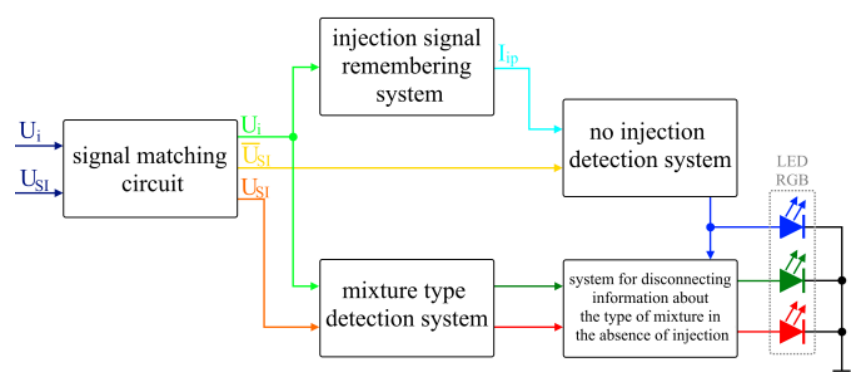

Fig. 6. Block diagram of the indicator of the type of a combustion mixture used to supply an SI engine with direct fuel injection

The electronic circuit has the form of a double-sided printed circuit board placed in the housing. It is connected to the car installation through an eight-pin connector (Fig. 7a). A three-colour LED diode informing the driver about the type of a mixture is mounted in the dashboard of the vehicle (Fig. 7b).
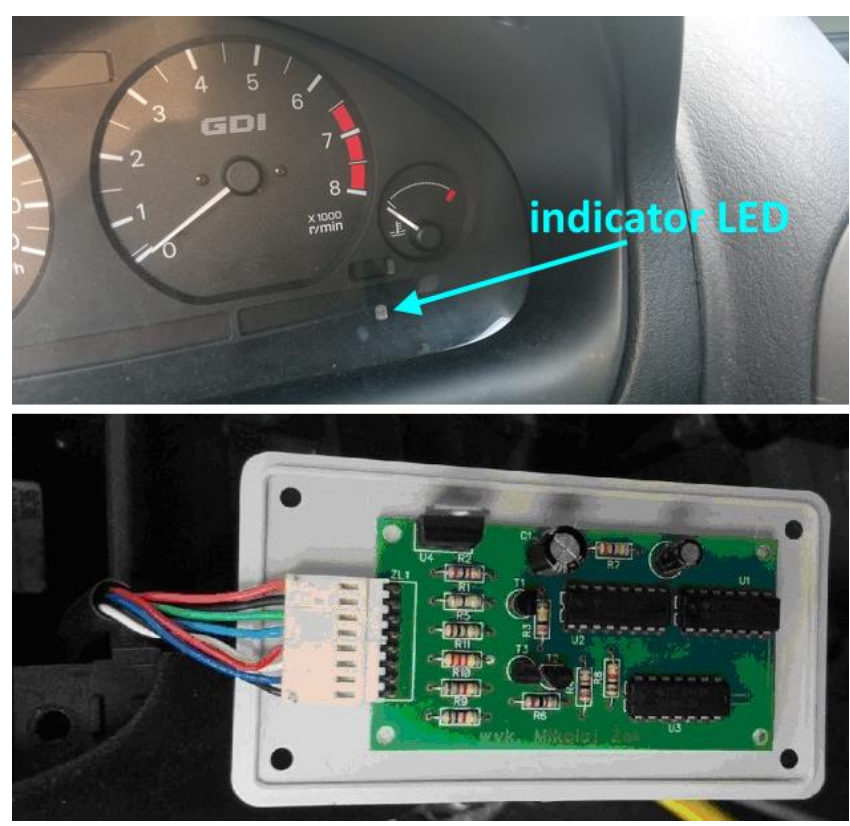

Fig. 7. Electronic circuit of the indicator and the location of its components

\subsection{Verification of the mixture type indicator electronic systems}

The developed and constructed mixture type indicator was tested to verify its operation. The research consisted in the analysis of simultaneously registered signals:

- fuel injection $\mathrm{U}_{\mathrm{i}}$ and ignition $\mathrm{U}_{\mathrm{SI}}$ for the first cylinder,

- injection memory $\mathrm{I}_{\mathrm{ip}}$,

- controlling a three-colour LED.

The signal registration was made with a PC equipped with a GAGE A/C converter card. Due to the short injection times $(<1 \mathrm{~ms})$, the sampling time was set to $20 \mu \mathrm{s}$. The trial time was set to $10 \mathrm{~s}$. During this time, the driver operated the accelerator pedal in such a way that the indicator changed the indication of the type of mixture several times (to change the colour of the LED diode). The results of one of the concluded tests are shown in Fig. 8.

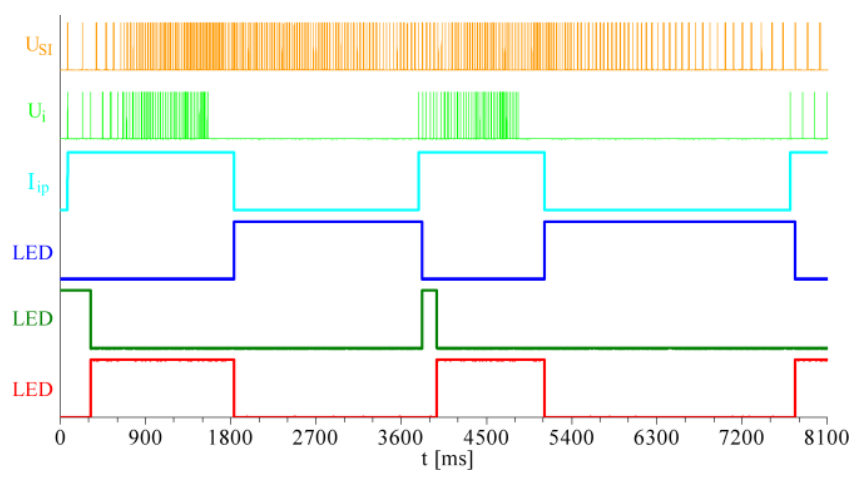

Fig. 8. Test results for the indicator of the type of a mixture

All signals in the figure above are two-state waveforms. Their colours are directly related to the signals in the block diagram (Fig. 6). Ignition signal $\mathrm{U}_{\mathrm{SI}}$ shows the ignition pulses where high state means the current flow through the primary winding of the ignition coil. Injection signal $U_{i}$ shows injection pulses, where the high state means the current flow through the injector winding. High state of the 
injection memory signal $I_{i p}$ shows information about the injection occurrence over the time $t_{i p m}$. Time $t_{i p n}$ is selected in such a way that the information about the injection occurrence is remembered until the moment of ignition in the next cycle of work at the lowest possible rotational speed of the engine. If a blue LED signal is high, it is emitting blue light. If a green LED signal is high, it is emitting green light. If a red LED signal is high, it is emitting blue light.

The assessment of the correctness of the operation of the mixture type indicator was based on the analysis of the recorded waveforms of the above-mentioned signals. For this purpose, Fig. 9 shows the signals from Fig. 8 for the characteristic periods in which the indication changes appear.
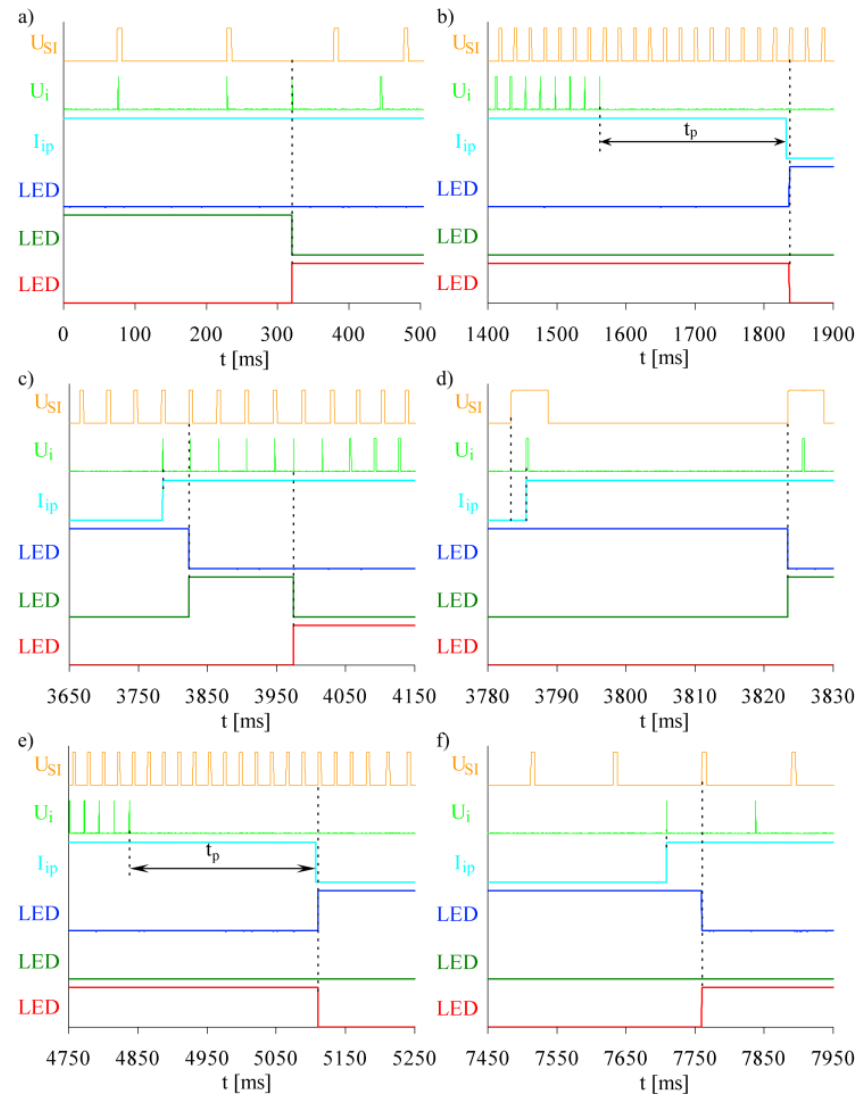

Fig. 9. The results of the test of the indicator of the type of mixture at the characteristic periods

Figure 9a presents the signals recorded within $500 \mathrm{~ms}$ from the start of the measurement. In the two first cycles, the fuel injection signal occurs simultaneously with the ignition signal, which indicates that the engine is supplied with a stratified mixture. During this time, the LED diode emits green light. In the third cycle, the fuel injection signal does not occur simultaneously with the ignition signal, which indicates that the engine is supplied with a homogeneous mixture. At the moment of the rising slope of the injection pulse, the colour of the light emitted by the LED diode changes to red. Figure $9 \mathrm{~b}$ shows the disappearance of injection pulses. This state causes that after time $t_{\text {ipm }}$, signal $\mathrm{I}_{\mathrm{ip}}$ changes to low. The closest rising slope of the ignition signal turns the LED diode to blue. Figure 9c shows the reappearance of injection pulses. The first one is remem- bered by changing the $\mathrm{I}_{\mathrm{ip}}$ signal into high. After this moment, the first ignition impulse will switch off the blue colour of the LED diode with the use of the rising slope. At the same time, the colour indicating the type of a mixture will be turned on. The mutual position of the ignition and injection pulses (the type of a mixture) is verified at every rising slope of the injection signal. Figure 9d explains why only during the second cycle after the injection there is a shut down of the blue colour of the indicator diode. Time on Figs $9 \mathrm{~b}$ and $9 \mathrm{e}$ is equal to the duration of several cycles. This causes the indicator to show no delayed injection. It does not matter much for a driver, as it is about $1 / 4$ second. On the other hand, it allows the indicator to work properly at a very low rotational speed, e.g. $500 \mathrm{rpm}$. The waveforms shown in Fig. 9, similarly to Fig. 9c, show the change of indication after the disappearance of injection pulses. Figure 9f shows the reappearance of injection pulses and the change of indication. This time, resuming a fuel injection creates a homogeneous mixture.

It can be concluded that the indicator correctly indicates the type of a fuel mixture that is being supplied to the engine of the car. The indication is carried out by the colour of the LED diode. The indicator reacts to a change in the type of a mixture created in less than one engine operation cycle, with the exception of no injection indication. The no fuel injection indication appears approximately $1 / 4$ seconds after the last fuel injection. The time is short enough for the indicator to work correctly.

\section{The assessment of the usefulness of the mixture type indicator for an economical driving style}

\subsection{Research methodology}

The method of planned and conducted research results from the concept of using the fuel mixture indicator in maintaining an economic driving style. The indicator as a device is to help the driver to cover the longest possible section of the route while supplying the engine with a stratified mixture. The indicator diode seen by the driver is to help him to operate the accelerator pedal in such a way that he can cover the longest distance in an economical way. The indicator is not intended to put pressure on a driver, but to help him or her to learn the economical driving style that makes it possible to burn very poor mixtures.

The base of the test method for this research paper is the comparison of fuel consumption for the mapped route driven with and without the indicator. For the research to be reliable, the following criteria were adopted:

- the route should be as long as possible (e.g. several dozen kilometers),

- the route should be completed in similar road conditions (e.g. at the same time of day, at a similar average speed),

- the route should be completed in similar weather conditions (e.g. dry road surface, no strong wind, similar temperature),

- the car should be driven by the same driver,

- the driver should be able to use the indications of the indicator so as to complete the largest possible part of the route on the indication corresponding to the stratified mixture,

- the route should be completed several times. 


\subsection{Plan and the course of research}

In order to meet the criteria resulting from the research methodology, a car was used for everyday commuting. This enabled the reduction of the costs and time for conducting research. A route with a length of approximately $84 \mathrm{~km}$ has been adopted, consisting of two parts: commuting to work for approx. 48 kilometers and returning approx. $37 \mathrm{~km}$. The map of the route is shown in Fig. 10.

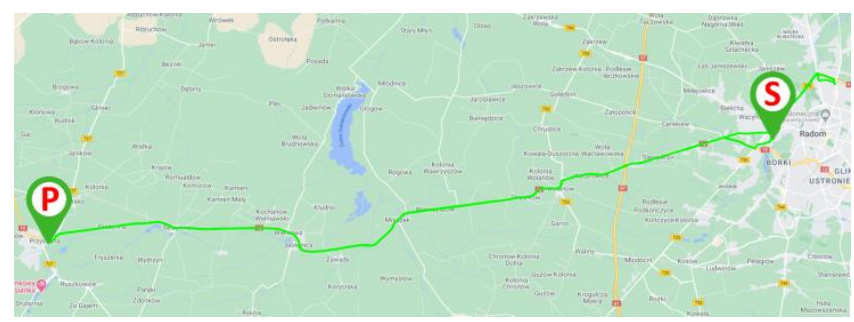

Fig. 10. The map with a marked daily route

The route passes through the urban and non-urban areas. A speed limit of $70 \mathrm{~km} / \mathrm{h}$ applies over a long distance. The first $10 \mathrm{~km}$ of the first route is located within the city limits of Radom. The remaining $37 \mathrm{~km}$ are the route to Przysucha on the national road No. 12. The second part of the route is the return to Radom by the national road No. 12, which is the same one. The first part of the route was driven in the morning between $7^{\frac{15}{5}}$ and $8^{\underline{30}}$ (Fig. 11). The second part of the route was driven in the afternoon between $16^{0.5}$ and $17^{15}$ (Fig. 12).

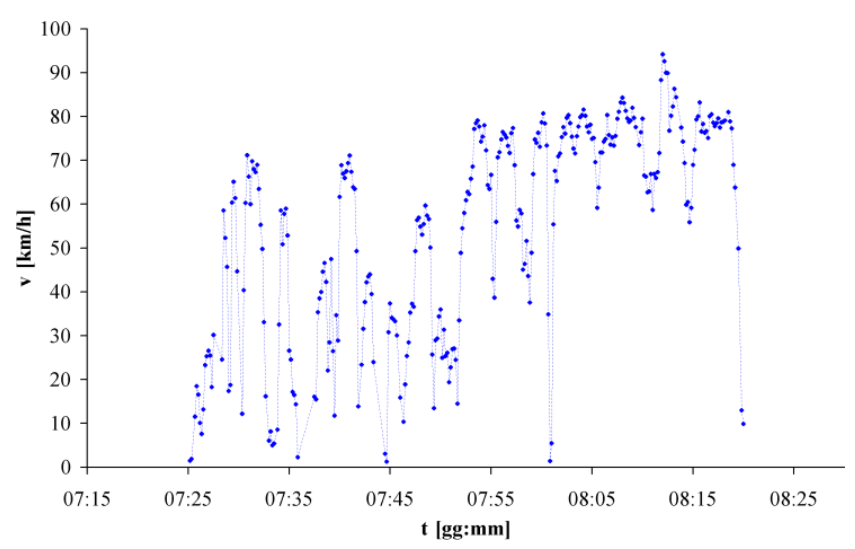

Fig. 11. Speed and time of day during the exemplary run of the first part of the route

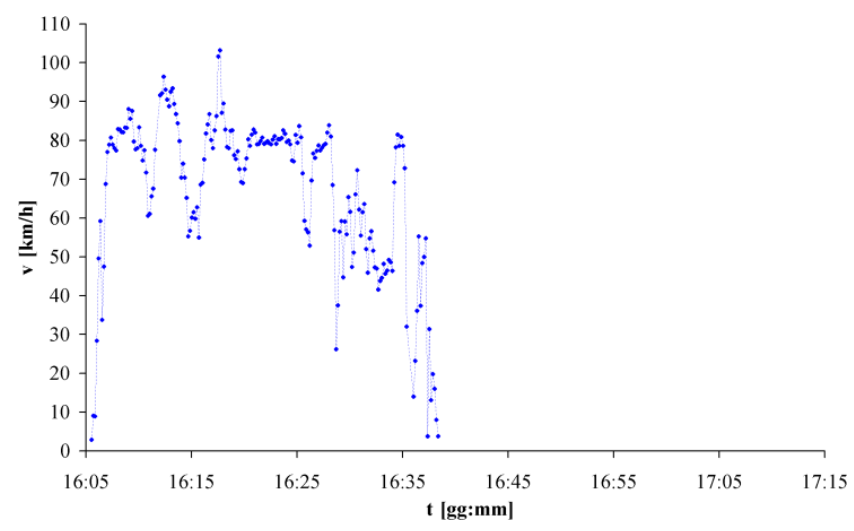

Fig. 12. Speed and time of day during the exemplary run of the second part of the route
The research was conducted in March and April 2021. Ten runs of the route were analyzed with the use of the indicator and five without the use of the indicator (the driver did not see the indication). Only those runs, which took place in similar weather conditions, were selected. Dry road surface, similar temperature (approx. 10 degrees Celsius) and no strong wind qualified the run for the analysis. In order to assess the repeatability of the driving cycles, vehicle speeds were presented and compared as a function of the road (Fig. 13). Fuel consumption was measured during each trip of the route (Table 2).

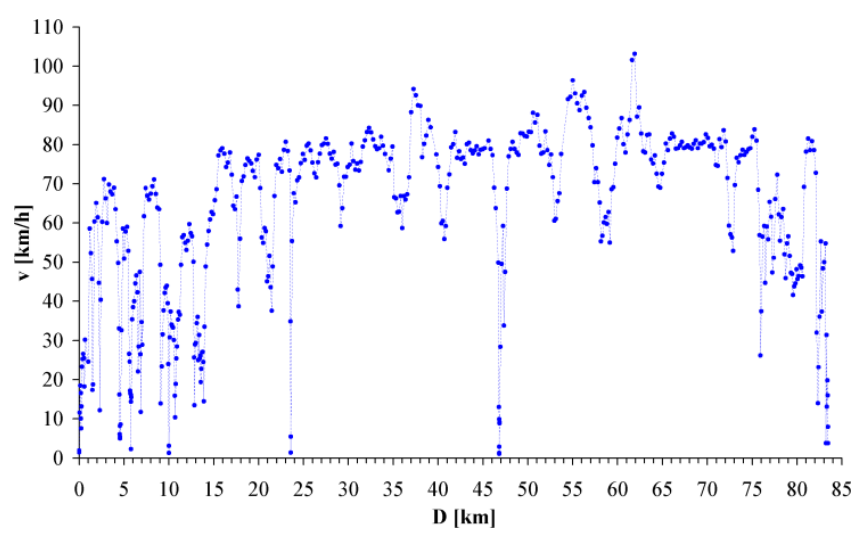

Fig. 13. Speed of travel at individual stages of the route during the exemplary run

During all the runs, the indications of the indicator were recorded every half a second. Examples of indications during the run in which the driver did not use the indicator (the indicator was covered) are shown in Fig. 14a. Figure 14b shows an example of an indication during which the driver uses the indicator.

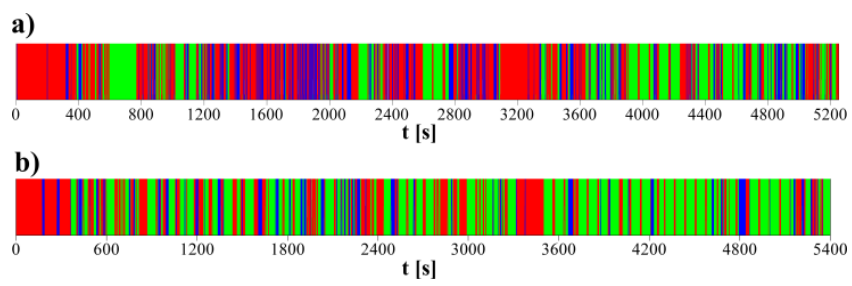

Fig. 14. Registration of the indicator operating during the run: a) in which the driver does not use the indications, $b$ ) in which the driver uses the indications

\subsection{Analysis of research results}

Figure 14a shows the recording of an indicator that is invisible to the driver during the work. The run lasted 5250 seconds. Figure $14 \mathrm{~b}$ shows the recording of an indicator that is visible to the driver during the work. The run lasted 5400 seconds. Visually, it can be assessed that the use of the indicator significantly increased the driving time on a stratified mixture, i.e. economical one (green colour). Table 1 presents numerically the times for the runs shown in Fig. 14 with the division into the first and second part of the route. 
Table 1. Route times for the cases shown in Fig. 14, divided into the first and the second part of the route and with the percentage share of each indication

\begin{tabular}{|c|c|c|c|c|c|c|c|c|c|}
\hline & \multicolumn{3}{|c|}{$\begin{array}{l}\text { Travel time for the } \\
\text { first part of the route }\end{array}$} & \multicolumn{3}{|c|}{$\begin{array}{l}\text { Travel time for the } \\
\text { second part of the } \\
\text { route }\end{array}$} & \multicolumn{3}{|c|}{$\begin{array}{l}\text { Time of travel } \\
\text { of the entire route }\end{array}$} \\
\hline & \multirow{2}{*}{\begin{tabular}{|c|} 
Total \\
{$[\mathrm{s}]$} \\
\end{tabular}} & \multicolumn{2}{|c|}{$\begin{array}{l}\text { With an } \\
\text { indication }\end{array}$} & \multirow{2}{*}{$\begin{array}{c}\text { Total } \\
{[\mathrm{s}]} \\
\end{array}$} & \multicolumn{2}{|c|}{$\begin{array}{l}\text { With an } \\
\text { indication }\end{array}$} & \multirow{2}{*}{$\begin{array}{c}\text { Total } \\
{[\mathrm{s}]} \\
\end{array}$} & \multicolumn{2}{|c|}{$\begin{array}{l}\text { With an } \\
\text { indication }\end{array}$} \\
\hline & & {$[\mathrm{s}]$} & [\%] & & {$[\mathrm{s}]$} & {$[\%]$} & & {$[\mathrm{s}]$} & {$[\%]$} \\
\hline \multirow{3}{*}{$\begin{array}{l}\text { Without } \\
\text { the help } \\
\text { of the } \\
\text { indicator }\end{array}$} & \multirow{3}{*}{3100} & 907.5 & 29.3 & \multirow{3}{*}{2150} & 1069 & 49.7 & \multirow{3}{*}{5250} & 1976.5 & 37. \\
\hline & & 1725.5 & 55.7 & & 824 & 38.3 & & 2549.5 & 48. \\
\hline & & 467 & 15.1 & & 257 & 12 & & 724 & 13. \\
\hline \multirow{3}{*}{$\begin{array}{l}\text { With the } \\
\text { help of } \\
\text { an } \\
\text { indicator }\end{array}$} & \multirow{3}{*}{3300} & 1753.5 & 53.1 & \multirow{3}{*}{2100} & 1441 & 68.6 & \multirow{3}{*}{5400} & 3194.5 & 59. \\
\hline & & 1234 & 37.4 & & 500.5 & 23.8 & & 1734.5 & 32. \\
\hline & & 312.5 & 9.5 & & 158.5 & 7.5 & & 471 & 8.7 \\
\hline
\end{tabular}

The numerical and percentage values presented in the table clearly confirm that the driver using the fuel-air mixture type indicator was able to drive a much larger part of the route on the stratified mixture. Measurements of fuel consumption (Table 2) confirm that the operation of the engine in a stratified mixture is more economical.

Table 2. Fuel consumption for individual trips of the route

\begin{tabular}{|c|c|c|c|}
\hline \multirow{2}{*}{ Trip number } & Use of the indicator & \multicolumn{2}{|c|}{ Fuel consumption } \\
\cline { 2 - 4 } & {$[$ yes $/$ no] } & {$\left[\mathrm{dm}^{3}\right]$} & {$\left[\mathrm{dm}^{3} / 100 \mathrm{~km}\right]$} \\
\hline 1. & yes & 5.27 & 6.27 \\
\hline 2. & no & 5.8 & 6.90 \\
\hline 3. & yes & 5.26 & 6.26 \\
\hline 4. & no & 5.9 & 7.02 \\
\hline 5. & yes & 5.33 & 6.35 \\
\hline 6. & no & 5.87 & 6.99 \\
\hline 7. & yes & 5.24 & 6.24 \\
\hline 8. & no & 5.85 & 6.96 \\
\hline 9. & yes & 5.25 & 6.25 \\
\hline 10. & no & 5.88 & 7.00 \\
\hline
\end{tabular}

\section{Nomenclature}

$\begin{array}{ll}\text { A/C } & \text { analog to digital converter } \\ \text { D } & \text { distance } \\ \text { ECU } & \text { electronic control unit } \\ \text { GDI } & \text { gasoline direct injection } \\ \mathrm{I}_{\text {ip }} & \text { injection pulse indicator } \\ \mathrm{n} & \text { engine speed } \\ \mathrm{RGB} & \text { red green blue } \\ \mathrm{SI} & \text { spark ignition } \\ \mathrm{U}_{\mathrm{i}} & \text { injection control signal }\end{array}$

The average value of fuel consumption for trips using the indicator was $6.27 \mathrm{dm}^{3} / 100 \mathrm{~km}$, while for trips without using the indicator $6.98 \mathrm{dm}^{3} / 100 \mathrm{~km}$. Thus, the fuel economy resulting from the economical driving style allowed by the use of the fuel mixture indicator is $10.07 \%$.

\section{Summary}

The article presents a simple electronic mixture type indicator. It detects what mixture the engine with direct fuel injection is supplied with. For operation, it uses signals generated by the engine control unit. As a result of the research, it was confirmed that the information generated by the indicator helps the driver to drive more economically. The savings in fuel consumption in relation to driving without the indicator are approx. 10\%. They result from deliberate and confirmed by indication driving on a stratified mixture. Driving a longer distance with the engine supplied with a stratified mixture (more economical) requires the driver to drive in a proper style. The indicator's usefulness is evidenced by the driving recording shown in Fig. $14 \mathrm{a}$ in the range from 1200 to 2000 seconds, where the driver, trying to maintain a constant speed, was driving on a homogeneous mixture with short-term fuel cut-offs. Slow acceleration to the target speed is also inappropriate from the point of view of driving economy. It takes place while supplying with a homogeneous (uneconomical) mixture for a long time. From time to time (about 1 minute), the ECU changes the type of mixture from stratified to homogeneous. This change takes approximately 10 seconds. During this time, the driver should not change the position of the accelerator pedal or increase the speed and then restore the position of the accelerator pedal until the indicator shows a stratified mixture.

The developed electronic indicator and the conducted research allowed to clearly and positively verify its usefulness in an economical driving style.

\section{Bibliography}

[1] LAKE, T., SAPSFORD, S., STOKES, J. et al. Simulation and development experience of a stratified charge gasoline direct injection engine. SAE Technical Paper 962014. 1996. https://doi.org/10.4271/962014

[2] PIELECHA, I. Diagnostics of stratified charge combustion under the conditions of multiple gasoline direct injection. Journal of Thermal Analysis and Calorimetry. 2014, 118, 217-225. https://doi.org/10.1007/s10973-014-3956-3
$\mathrm{U}_{\mathrm{SI}} \quad$ ignition control signal

TDC top dead centre

TTL transistor-transistor logic

$\mathrm{t}_{\mathrm{i}} \quad$ injection time

$\mathrm{t}_{\mathrm{ipm}} \quad$ injection pulse memorization time

$\mathrm{v} \quad$ car speed

$\lambda \quad$ air-fuel equivalence ratio
[3] TSAI, W.-C., ZHAN, T.-S. An experimental characterization for injection quantity of a high-pressure injector in GDI engines. Journal of Low Power Electronics and Applications. 2018, 8(36). https://doi.org/10.3390/jlpea8040036

[4] DURONIO, F., DE VITA, A., ALLOCCA, L. et al. Gasoline direct injection engines - a review of latest technologies and trends. Part 1: Spray breakup process. Fuel. 2020, 265, 116948. https://doi.org/10.1016/j.fuel.2019.116948 
[5] DURONIO, F., DE VITA, A., MONTANARO, A. et al Gasoline direct injection engines - a review of latest technologies and trends. Part 2. Fuel. 2020, 265, 116947, https://doi.org/10.1016/j.fuel.2019.116947

[6] LOIS, D., WANG, Y., BOGGIO-MARZET, A. et al. Multivariate analysis of fuel consumption related to eco-driving: Interaction of driving patterns and external factors. Transportation Research Part D: Transport and Environment. 2019, 72, 232-242. https://doi.org/10.1016/j.trd.2019.05.001

\footnotetext{
Zbigniew Wołczyński, DEng. - Faculty of Mechanical Engineering, Kazimierz Pulaski University of Technology and Humanities in Radom.

e-mail: z.wolczynski@uthrad.pl
}

[7] ŻAK, M. Development of the fuel mixture indicator for the GDI engine of the Mitsubishi Carisma. Doctoral thesis. Kazimierz Pulaski University of Technology and Humanities in Radom, Faculty of Mechanical Engineering. Radom 2021.

[8] WOŁCZYŃSKI, Z. Identification of properties of GDI engine and its control system. Combustion Engines. 2011, 146(3), PTNSS-2011-SC-116.

Mikołaj Żak, Eng. - Faculty of Mechanical Engineering, Kazimierz Pulaski University of Technology and Humanities in Radom.

e-mail:mikunio107@gmail.com 